\title{
Forward Speed Prediction of a Free-Running Wave-Propelled Boat
}

\author{
James A. Bowker, Mingyi Tan, and Nicholas Charles Townsend ${ }^{(1)}$
}

\begin{abstract}
Wave-propelled boats utilize submerged flapping foils to convert wave energy directly into propulsion. For platforms that are solely propelled using submerged flapping foils, predicting the forward speed is challenging as it is time varying and dependent on the coupled responses of the wave-induced hull motions (surge, heave, and pitch) and the foil flapping motion (driven by the waveinduced hull motions and incident wavy flow). To ascertain the free-running response of wave-propelled boats, this article presents a hybrid discrete time-domain numerical model and experimental results from a prototype wave-propelled autonomous surface vehicle (ASV) with forward and aft (tandem) flapping foils. Results from a series of free-running experiments in regular head waves, over a range of wave frequencies for three different foil locations, are presented and used to validate the numerical model. The model was found to show good agreement with the experimental results, capturing the coupled dynamics of the vessel and foils and oscillating forward speed, over a range of wave frequencies and foil locations. The model and results provide a valuable insight for the design of wave-propelled boats.
\end{abstract}

Index Terms-Augmented propulsion, autonomous surface vehicles (ASVs), flapping foils, robotics, wave energy, wavepropelled boats.

\section{INTRODUCTION}

\section{A. Motivation}

M ARINE craft operating in waves experience waveinduced motions. This transfer in energy is usually undesirable due to increasing resistance and powering requirements. However, through the addition of submerged flapping foils, this energy can be exploited for propulsion. In suitable wave conditions, the wave-induced flapping motion of submerged flapping foils combined with the incident wavy flow results in a time-average thrust force. This thrust can be used to augment the existing propulsion [1], [2], significantly reducing fuel consumption, or used as the primary propulsor [3], [4], eliminating the necessity to carry propulsive energy reserves (e.g., fuel or batteries) for entire journeys. This approach has significant potential for marine vessels, especially for small unmanned vessels, such as autonomous surface vehicles (ASVs), where low cost, low power, and long endurance systems are required.

Manuscript received October 10, 2019; revised March 6, 2020; accepted April 20, 2020. This work was supported by the Lloyd's Register Foundation. (Corresponding author: Nicholas Charles Townsend.)

Associate Editor: K. von Ellenrieder.

James A. Bowker, Mingyi Tan, and Nicholas Charles Townsend are with the Faculty of Engineering and Physical Sciences, University of Southampton, Southampton S016 7QF, U.K. (e-mail: bowkerja@googlemail.com; m.tan@soton.ac.uk; nick@soton.ac.uk).

Digital Object Identifier 10.1109/JOE.2020.2990143

\section{B. Background}

Wave-augmented propulsion was first demonstrated almost 120 years ago through a series of full scale trials of a 13-ft boat with flapping foils mounted at the bow and the stern [5]. Initial developments including models and full scale trials were only reported as interesting ideas rather than academic studies [6], [7]. Other than a full scale prototype built by Gause [8], wavepropelled boats did not receive significant attention until the 1970s when Jakobsen started a series of model experiments and full scale trials. Jakobsen [9] installed a spring-loaded flapping foil at the bow of a model and performed experiments in a wave basin. Further developments led to the first trials on-board a commercial vessel called M/S Kystfangst [10]. The trials proved the full scale feasibility of submerged foils to reduce the motions of a vessel and generate thrust to augment the main propulsion. A similar full scale trial was conducted on a Russian trawler, which showed that a pair of submerged foils at the bow could significantly contribute to the propulsive thrust and reduce the pitch motion of the vessel by up to $50 \%$ [11]. In parallel to the developments in Europe, Terao in Japan conducted a simplified free-running experimental study with a surface boat and submerged flapping foils in waves, which under certain conditions achieved self-propulsion [12]. A similar set-up was installed on a fishing boat in Japan by Isshiki et al.[13]. This research led to the wave-driven flapping foil wave-propelled Catamaran the Suntory Mermaid II, which crossed the Pacific Ocean in 110 days in 2008, which remains the longest voyage undertaken by a manned wave-propelled boat [14]. Later this was developed into full scale trials of a wave-devouring propulsion system (WDPS), a wave-propelled ASV catamaran design [15], [16]. More recently, AutoNaut Ltd., Chichester, U.K. [3] has developed a commercial wave-propelled ASV with submerged foils driven by the wave-induced pitch and heave motion of the surface vehicle (similar to that by Linden). In addition, Liquid Robotics, Sunnyvale, CA, USA, has developed a commercial wave-propelled ASV platform (the Waveglider) with a set of tethered submerged foils driven by the waveinduced heave motion of the floating platform [17]. Furthermore, Wavefoil AS, Trondheim, Norway, has recently demonstrated wave-augmented propulsion of a 45-m ferry using submerged bow foils [18].

\section{Literature Review}

Recent research has focused on the analysis of heave-driven mechanisms for wave propulsion, for example, [19]-[22]. Zhou 
et al. [22] presented a simplified 2-DOF numerical model using Kane's method to solve the coupled dynamics of the surface vessel and submerged foils to predict the forward speed of a Waveglider. The numerical model, which neglects the pitch motion and assumes the heave motion follows a sinusoidal wave profile, was found to show reasonable agreement with the experimental results [22]. Yu et al. [20] modeled the forward speed of a floating mobile buoy with a submerged foil, assuming a known heave motion, showing that the forward speed increases with the buoy heave motion. Furthermore, Liu et al. [19] compared the experimental results from a prototype Waveglider system to CFD simulations, finding good agreement; whereas Tian et al. [21] presented a Lagrangian approach to model the dynamics of a heave-driven system. In addition, a regression method has also been applied to solve for the forward speed of a heave-driven system [23], however, this method relies on extensive data acquired on the forward speed and heading of an in-situ wave-propelled boat; that is, free-running numerical models have been developed to predict the forward speed of a heave-driven wave-propelled vessel. The majority of approaches assume that the wave-induced heave motion of the submerged foils is equivalent to the wave amplitude and neglect the platform pitch motion and the effect of the local wave particle velocities. As the foils are submerged to a significant depth, these assumptions are acceptable for a heave-driven system.

For pitch-driven wave propulsion systems, the analysis is more complex, as it is necessary to account for the wave-induced pitch of the vessel as well as the vessel heave response. Liu et al. [24] conducted a numerical study that investigated this mode of propulsion in regular waves. The vessel motions are solved in the frequency domain and coupled with the submerged foil motions via two springs. The hydrodynamic forces of the flapping foil are resolved using Wu's theory [25], and the results show that the location of the foil relative to the vessel is of key importance. Xie et al. [26] published a detailed computational fluid dynamics (CFD) analysis of a tandem foil set-up for a wave-propelled unmanned catamaran. Although the analysis is detailed in terms of the resultant hydrodynamic forces, the analysis assumes that the foil is not flapping (i.e., does not pitch about its own axis) and there is no physical interaction between the submerged foils and the catamaran motions (i.e., the presence of the foils has no effect on the motions of the catamaran). The results do, however, show that the forward foil generates more thrust than the aft foil in head waves, which demonstrates the importance of foil location on the propulsive performance. Previous efforts have involved methods based on assuming the forward speed and adjusting the forward speed based on the apparent thrust [27] and an empirical solution specific to a particular hull shape [13]. More recently, a method has been derived by significantly simplifying the vessel motions and neglecting the wave-induced surge force [20]. In addition, several methods have been implemented for fixed speed numerical solutions including [28]-[30]. However, these simulations model the flapping foils as auxiliary propulsors and a predefined ship speed is applied; that is, although free-running experiments and in situ trials have been completed, a numerical model that accurately captures the forward speed of a pitch-driven freerunning wave-propelled vessel in waves remains challenging.

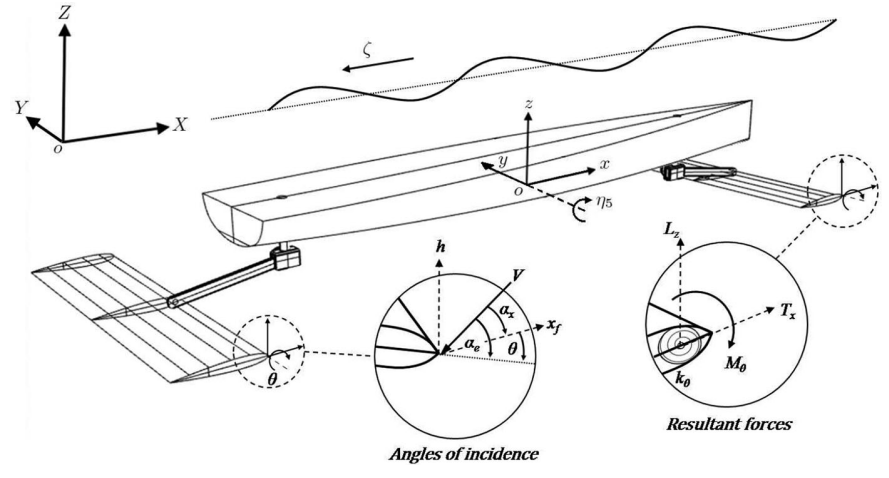

Fig. 1. Frames of reference.

\section{Contribution and Outline}

This article presents a hybrid discrete time-domain numerical model of the free-running response of a wave-propelled boat with forward and aft (tandem) flapping foils. Results from a series of free-running experiments in regular head waves, over a range of wave frequencies for three different foil locations are presented and used to validate the numerical model. This article is structured as follows: Section II presents the numerical model that captures the coupled dynamics of the vessel motions, foil response, and (oscillating) forward speed. Section III presents the experimental results from a prototype free-running wavepropelled boat and Section IV presents the comparison between the simulated and experimental data. A discussion of the results, including the implications for the design of wave-propelled vessels, is made in Section $\mathrm{V}$ and the conclusions are presented in Section VI.

\section{NUMERICAL MODELING}

\section{A. Approach}

To model the free-running response of a wave-propelled boat, capturing the coupled dynamics of the vessel and foils, a hybrid discrete time-domain numerical model was developed. The model evaluates the hull and foil responses and determines the resultant thrust generation with respect to the encountered wave profile at each time step. This approach, of updating and evaluating the hull and foil motions including the encountered wave frequency and frequency-dependent hydrodynamic coefficients at each instance of time $\left(t_{n}\right)$, enabled the free-running response (of the hull, foil, and forward speed) to be determined.

\section{B. Definitions and Reference Frames}

The vessel heave $\left(\eta_{3}\right)$ and pitch $\left(\eta_{5}\right)$ motions were evaluated with respect to the inertial frame of reference (oxyz) and the vessel surge $\left(\eta_{1}\right)$ was evaluated with respect to the fixed inertial $(o X Y Z)$ axis frame, as shown in Fig. 1. Here, the inertia reference frame (oxyz) represents the vessel equilibrium or seakeeping axis frame, which moves with the vessel's mean forward speed and the pitch is taken as the rotation about the vessel's longitudinal center of gravity (LCG). The vessel-induced foil heave $(h)$ was evaluated as a remote location on the vessel, at a depth below the waterline $\left(d_{f}\right)$ and the pitch of the foil 
$(\theta)$ was evaluated about the pivot point $a$. In this study, the wave profile was assumed to be sinusoidal, propagating in the negative $x$-direction (to represent head waves and a positive forward motion of the vessel away from the origin) defined by

$$
\zeta(t)=\zeta_{0} \sin (k x(t)+\omega t)
$$

where $\zeta_{0}$ represents the wave amplitude, $k$ is the wave number, and $\omega$ is the wave frequency.

\section{Vessel Motions}

The vessel motions were represented by the coupled heave $\left(\eta_{3}\right)$ and pitch $\left(\eta_{5}\right)$ ordinary differential equations

$$
\begin{gathered}
\left(M+A_{33}\right) \ddot{\eta}_{3}+B_{33} \dot{\eta}_{3}+C_{33} \eta_{3}+A_{35} \ddot{\eta}_{5}+B_{35} \dot{\eta}_{5} \\
+C_{35} \eta_{5}=F_{3}{ }^{B}+\sum_{i=1}^{2} F_{3_{i}}{ }^{F} \\
\left(I+A_{55}\right) \ddot{\eta}_{5}+B_{55} \dot{\eta}_{5}+C_{55} \eta_{5}+A_{53} \ddot{\eta}_{3}+B_{53} \dot{\eta}_{3} \\
+C_{53} \eta_{3}=F_{5}{ }^{B}+\sum_{i=1}^{2} F_{5_{i}}{ }^{F}
\end{gathered}
$$

where $F^{B}$ represents the excitation forces and moments due to the waves acting on the hull and $F^{F}$ represents the forces and moments due to the submerged foils. Subscripts 3 and 5 refer to the heave and pitch components, respectively, and $A$ and $B$ represent the frequency-dependent added mass and damping coefficients, respectively. Here, the Coriolis effect due to the forward speed in the heave dynamics is assumed negligible as the vessel speed is low. $C$ represents the hydrostatic restoring coefficients, and $M$ and $I$ represent the total mass and pitch moment of inertia of the vessel including the foils. Subscript $i$ denotes the foil number where $i=1$ refers to the aft foil and $i=2$ is the forward foil. The hydrodynamic coefficients were evaluated using a conformal mapping strip theory method, assuming a slender, rigid and wall-sided vessel, and small amplitude motions [31] as

$$
\begin{aligned}
& A_{33}{ }^{0}=\int_{L} a_{33} d \xi \\
& A_{33}=A_{33}{ }^{0}-\frac{U}{\omega_{e}{ }^{2}} b_{33}{ }^{A} \\
& B_{33}{ }^{0}=\int_{L} b_{33} d \xi \\
& A_{35}=-\int_{L} \xi a_{33} d \xi-\frac{U}{\omega_{e}^{2}} B_{33}{ }^{0}+\frac{U}{\omega_{e}^{2}} \xi^{A} b_{33}{ }^{A}-\frac{U^{2}}{\omega_{e}^{2}} a_{33}{ }^{A} \\
& A_{53}=-\int_{L} \xi a_{33} d \xi+\frac{U}{\omega_{e}{ }^{2}} B_{33}{ }^{0}+\frac{U}{\omega_{e}{ }^{2}} \xi^{A} b_{33}{ }^{A} \\
& A_{55}=\int_{L} \xi^{2} a_{33} d \xi+\frac{U^{2}}{\omega_{e}{ }^{2}} A_{33}{ }^{0}-\frac{U}{\omega_{e}{ }^{2}}\left(\xi^{A}\right)^{2} b_{33}{ }^{A}+\frac{U^{2}}{\omega_{e}{ }^{2}} \xi^{A} a_{33}{ }^{A} \\
& B_{33}=B_{33}{ }^{0}+U a_{33}{ }^{A} \\
& B_{35}=-\int_{L} \xi b_{33} d \xi+U A_{33}{ }^{0}-U \xi^{A} a_{33}{ }^{A}-\frac{U^{2}}{\omega_{e}{ }^{2}} b_{33}{ }^{A} \\
& B_{53}=-\int_{L} \xi b_{33} d \xi-U A_{33}{ }^{0}-U \xi^{A} a_{33}{ }^{A} \\
& B_{55}=\int_{L} \xi^{2} b_{33} d \xi+\frac{U^{2}}{\omega_{e}^{2}} B_{33}{ }^{0}+U\left(\xi^{A}\right)^{2} a_{33}{ }^{A}+\frac{U^{2}}{\omega_{e}{ }^{2}} \xi^{A} b_{33}{ }^{A} \\
& C_{33}=\rho g \int_{L} b_{\xi} d \xi=\rho g A_{\mathrm{WP}} \\
& C_{35}=C_{53}=-\rho g \int_{L} \xi b_{\xi} d \xi=-\rho g M_{\mathrm{WP}} \\
& C_{55}=\rho g \int_{L} \xi^{2} b_{\xi} d \xi=\rho g I_{\mathrm{WP}}
\end{aligned}
$$

and, similarly, the excitation forces (the integral of the FroudeKrylov force and the diffraction force exerted on each strip) were modeled as (based on [32])

$$
\begin{aligned}
F_{3}= & \zeta_{0} \int_{L} e^{i k \xi} e^{-k d_{\xi} s_{\xi}}\left[\rho g b-\omega\left(\omega_{e} a_{33}-i b_{33}\right)\right] d \xi \\
& -\zeta_{0} \frac{U}{i \omega_{e}} e^{i k \xi_{A}} e^{-k d_{\xi} s_{\xi}} \omega\left(\omega a_{33}{ }^{A}-i b_{33}{ }^{A}\right) \\
F_{5}= & -\zeta_{0} \int_{L} e^{i k \xi} e^{-k d_{\xi} s_{\xi}}\left[\xi\left(\rho g b-\omega\left(\omega_{e} a_{33}-i b_{33}\right)\right)\right. \\
& \left.-\zeta_{0} \frac{U}{i \omega_{e}} \omega\left(\omega a_{33}-i b_{33}\right)\right] d \xi \\
+ & \zeta_{0} \frac{U}{i \omega_{e}} e^{i k \xi_{A}} e^{-k d_{\xi} s_{\xi}} \omega \xi_{A}\left(\omega a_{33}{ }^{A}-i b_{33}{ }^{A}\right)
\end{aligned}
$$

where $b_{\xi}$ and $d_{\xi}$ represent the sectional beam and draft, respectively, and $s_{\xi}$ the sectional area coefficient (Sectional Area/ $\left.\left[b_{\xi} \times d_{\xi}\right]\right) . A_{\mathrm{WP}}, M_{\mathrm{WP}}$, and $I_{\mathrm{WP}}$ represent the water-plane area and the first and second moments of areas acting about the transverse axis located at the center of gravity, respectively. $U$ represents the forward speed of the vessel and $\omega_{e}$ represents the encounter frequency ( $\omega_{e}=\omega-k U$ for head waves). The terms $a_{33}^{A}$ and $b_{33}^{A}$ represent the aftmost sectional added mass and damping coefficients, to account for transom effects. The time-domain heave and pitch forcing terms were modeled as

$$
\begin{aligned}
& F_{3}{ }^{B}=\left|F_{3}\right| \sin \left(\delta+\varphi_{3}\right) \\
& F_{5}{ }^{B}=\left|F_{5}\right| \sin \left(\delta+\varphi_{5}\right) .
\end{aligned}
$$

Here, the inclusion of the time-dependent variable $\delta=(k x+$ $\omega t)_{n-1}+\omega_{e} \Delta t$ is introduced and evaluated at each time step, to account for the changes in the vessel position in the waves, the forward speed $U$ and encounter frequency $\omega_{e}$.

\section{Foil Motions}

The submerged foils generate a thrust through the relative motion of the foils (due to the wave-induced hull motions) and the incident orbital wave profile. To determine the resultant vertical forces $\left(F_{3}^{F}\right)$ and moments acting on the vessel $\left(F_{5}^{F}\right)$ (due to the foils), first the foil heave motion and flow over the foils were determined and then the resultant hydrodynamic forces (lift, thrust/drag, and inertia) were resolved, in the $x$ and $z$ directions, following Theodorsen's theory of aerodynamic flutter; that is, assuming that the foil is a flat plate with small (foil) pitch angles with attached flow.

As the submerged foils are rigidly fixed to the vessel, the foil heave $(h)$ was assumed equivalent to a remote location on-board the vessel and modeled as

$$
h=-\sqrt{\left(x_{f}^{2}+d_{f}^{2}\right)} \sin \left(\tan ^{-1}\left|\frac{d_{f}}{x_{f}}\right| \pm \eta_{5}\right)+\eta_{3}
$$

where $x_{f}$ and $d_{f}$ represent the foil position in the $x$ and $z$ directions relative to the vessel LCG (i.e., the foil longitudinal position and depth). Furthermore, assuming deep-water and regular waves, the vertical and horizontal components of the 
fluid velocities (within the wave) can be expressed as

$$
\begin{aligned}
& u_{w}=\frac{g k \zeta_{0}}{\omega} e^{k d_{z}} \sin \left[k\left(x_{B}+x_{f}\right)+\omega t\right] \\
& v_{w}=\frac{g k \zeta_{0}}{\omega} e^{k d_{z}} \cos \left[k\left(x_{B}+x_{f}\right)+\omega t\right]
\end{aligned}
$$

and the relative horizontal $\left(u_{f}\right)$ velocity component, accounting for the vessel's forward speed $(U)$, and the vertical $\left(v_{f}\right)$ velocity component [the combination of the foil heave velocity and the vertical component of the wave particle orbital motions $\left(v_{w}\right)$ at the foil location] were modeled as

$$
\begin{aligned}
& u_{f}=U-u_{w} \\
& v_{f}=\dot{h}_{r}-\frac{c}{4}(1-2 a) \dot{\theta}
\end{aligned}
$$

at the $3 / 4$ th of chord location

where $x_{B}$ represents the position of the vessel LCG in the $x$ direction and $d_{z}$ the instantaneous foil depth. $\dot{h}_{r}$ represents the relative velocity between the foil heave velocity and the vertical component of the wave particle motions $\left(\dot{h}_{r}=\dot{h}-v_{w}\right)$ and $a$ is a nondimensional representation of the foil pivot point ( $a=$ -1 at the leading edge and $a=1$ at the trailing edge). For the simulations, the foil pivot point was assumed to be at the leading edge, i.e., $a=-1$.

The hydrodynamic lift force (due to the flow over the foil) was calculated at each time step as

$$
L_{C}=\frac{1}{2} \rho C_{L} U^{2} c s
$$

where $c$ and $s$ represent the chord and span length, respectively. The lift coefficient $\left(C_{L}\right)$, assuming small angles and following Prantl's lifting line approximation for finite span foils [33], was modeled as

$$
C_{L}=2 \pi \frac{\mathrm{AR}}{\mathrm{AR}+2} \alpha^{\prime}
$$

and the angle of attack $\left(\alpha^{\prime}\right)$ was resolved at the 3/4th of chord location as

$$
\alpha^{\prime}=C^{\prime}\left[\left(\frac{v_{f}}{u_{f}}\right)-\theta\right]
$$

where AR represents the aspect ratio (the span to foil area ratio, $\mathrm{AR}=s /(s \times c)$ and $C^{\prime}$ represents the Theodorsen lift deficiency coefficient, which accounts for a reduction in lift due to the unsteady oscillations of the flapping foil wake [34]. In this study, $C^{\prime}$ was approximately 0.52 over the range of investigated cases.

The moment about the pivot point due to the hydrodynamic lift force acting at the 1/4th of chord location was then modeled as

$$
M_{C}=L_{C}\left(\frac{c}{4}\right)(2 a+1)
$$

Similarly, the drag force $(D)$ was calculated at each time step as

$$
D=\frac{1}{2} \rho C_{D}(\alpha) V^{2} c s+D_{i}
$$

with respect to the instantaneous flow speed $[V=$ $\left.\sqrt{\left(u_{f}^{2}+v_{f}^{2}\right)}\right]$ and angle of attack at the 1/4th of chord location $\left[\alpha=\tan ^{-1}\left(v_{f} / u_{f}\right)-\theta\right]$. An induced drag $\left(D_{i}\right)$ term to account for the 3-D flow effects at the foil tips, applicable for foils of finite span [33] was introduced. This effect, approximated by Prandtl, was estimated as a proportion of the circulatory lift force as

$$
D_{i}=\frac{L_{C}^{2}}{\pi \mathrm{AR} e}
$$

where $e$ represents the planform efficiency ( $e=1$ for an elliptical wing).

In addition to the lift and drag forces, there are inertial forces and moments associated with accelerating the foil mass $\left(m_{f}\right)$ and the added mass $\left(m_{a}\right)$ of the surrounding fluid. In the $x$ direction, as the Froude number is small $\left(F_{n}<0.1\right)$, the foil added mass was assumed negligible and the inertial force $\left(D_{m}\right)$ was represented by

$$
D_{m}=m_{f}\left\{c\left[b_{g}-\frac{1}{2}(1+a)\right]\left(\ddot{\theta} \sin \theta+\dot{\theta}^{2} \cos \theta\right)\right\}
$$

where $b_{g}$ is a nondimensional representation of the center of gravity of the foil (i.e., $b_{g}=0$ at the leading edge and $b_{g}=1$ at the trailing edge). For the simulations, $b_{g}=1 / 3$. In the $z$ direction, the inertial force associated with accelerating the foil mass $\left(L_{m}\right)$ was modeled as

$$
L_{m}=m_{f}\left\{c\left[b_{g}-\frac{1}{2}(1+a)\right]\left(\ddot{\theta} \cos \theta-\dot{\theta}^{2} \sin \theta\right)+\ddot{h}\right\}
$$

and the inertial force associated with the added mass $\left(L_{\mathrm{NC}}\right)$ was modeled as

$$
L_{\mathrm{NC}}=m_{a}\left[\ddot{h}_{r}-\left(\frac{c}{2}\right) a \ddot{\theta}+U \dot{\theta}\right]
$$

where $\ddot{h}_{r}$ represent the relative heave acceleration of the foil and $m_{a}$ represents the added mass of the foil, approximated as a flat plate $\left[\pi \rho(c / 2)^{2} s\right][33]$.

Resolving the moments about the foil pivot point, the foil pitch (assumed to be constrained by a rotational spring), was then modeled (at each time step) as

$$
M_{C}-D \sin (\alpha)\left(\frac{c}{4}\right)(2 a+1)=I_{f} \ddot{\theta}+k_{\theta} \theta+M_{m}+M_{N C}
$$

where $I_{f}$ is the rotational inertia of the foil and $k_{\theta}$ is the spring constant. $M_{C}$ represents the moment about the pivot point due to the hydrodynamic lift force and $M_{m}$ and $M_{\mathrm{NC}}$ represent the moments due to the inertial forces modeled as

$$
M_{m}=m_{f} c\left[b_{g}-\frac{1}{2}(1+a)\right] \ddot{h} \cos \theta
$$

and

$$
M_{\mathrm{NC}}=m_{a}\left(\frac{c}{2}\right)\left[\left(\frac{c}{2}\right)\left(\frac{1}{8}+a^{2}\right) \ddot{\theta}-a \ddot{h}_{r}+\left(\frac{1}{2}-a\right) U \dot{\theta}\right] .
$$


The resultant vertical forces $\left(F_{3}{ }^{F}\right)$ and moments acting on the vessel $\left(F_{5}{ }^{F}\right)$ were then determined as

$$
\begin{aligned}
& {F_{3}}^{F}=\sum_{i=1}^{2} L_{z_{i}} \\
& F_{5}{ }^{F}=\sum_{i=1}^{2} x_{f_{i}} L_{z_{i}}
\end{aligned}
$$

where $L_{z}$ represents the resultant hydrodynamic and inertial forces in the $z$-direction; that is

$$
L_{z}=\left(L_{C}-L_{\mathrm{NC}}-L_{m}\right) \cos \left(\eta_{5}\right)-D_{m} \sin \left(\eta_{5}\right)+D \sin \left(\eta_{5}\right)
$$

and $T_{x}$ represents the resultant hydrodynamic and inertial forces in the $x$-direction, that is

$T_{x}=\left(L_{C}-L_{\mathrm{NC}}-L_{m}\right) \sin \left(\eta_{5}\right)+D_{m} \cos \left(\eta_{5}\right)-D \cos \left(\eta_{5}\right)$.

\section{E. Forward Speed}

Resolving the forces in the $x$-axis, the vessel surge motion $\left(\dot{\eta_{1}}=U\right)$ was modeled as

$$
T_{x}+F_{\zeta}=\left(M_{B}+A_{11}\right) \ddot{\eta}_{1}+B_{11} \dot{\eta}_{1}
$$

where the flapping foil thrust $T_{x}$ and the wave-induced surge force $F_{\zeta}$ represent the excitation forces and the inertial and hydrodynamic damping forces are characterized by the added mass and damping coefficients $A_{11}$ and $B_{11}$, respectively. The damping was assumed to be a derivative of the vessel's total resistance $R_{T}$ comprised of the bare hull resistance in calm water $R_{\mathrm{SW}}$, the added resistance due to the waves $R_{\mathrm{AW}}$, and an appendage resistance $R_{\mathrm{APP}}$ due to the additional submerged struts; that is

$$
B_{11}=\frac{d R_{T}}{d \dot{\eta}_{1}}=\frac{d\left(R_{\mathrm{SW}}+R_{\mathrm{AW}}+R_{\mathrm{APP}}\right)}{d \dot{\eta}_{1}} .
$$

The bare hull resistance $R_{\mathrm{SW}}$ was estimated using the ITTC' 57 empirical formula and a form factor [35] . The added resistance due to the waves $R_{\mathrm{AW}}$ was modeled following a momentum and energy method (considered the most robust solution due to its ability to accurately capture the peak resistance and its stability in short waves (large $\omega_{e} \sqrt{L / \lambda}$ ) ) [36] with additional terms to account for the presence of submerged foils as

$$
\begin{aligned}
R_{\mathrm{AW}}=\frac{1}{2} \frac{\omega^{3} e}{g} & {\left[\left(B_{33}+\frac{F_{L}}{U}\right) \eta_{3}{ }^{2}+\left(B_{55}+\frac{F_{L} x_{f_{i}}{ }^{2}}{U}\right) \eta_{5}{ }^{2}\right.} \\
& \left.-2\left(B_{35}+\frac{F_{L} x_{f_{i}}}{U}\right) \eta_{3} \eta_{5}\right]
\end{aligned}
$$

where $F_{L}=\pi \rho C^{\prime} U^{2} c s(\mathrm{AR} /(\mathrm{AR}+2))$ represents the simplified Prandtl lifting line force for an unsteady flapping foil [37]. The appendage resistance $R_{\mathrm{APP}}$ due to the additional submerged struts, was evaluated as a viscous drag force, expressed as

$$
R_{\mathrm{APP}}=\frac{1}{2} \rho C_{D_{A}} U^{2} A_{\mathrm{APP}}
$$

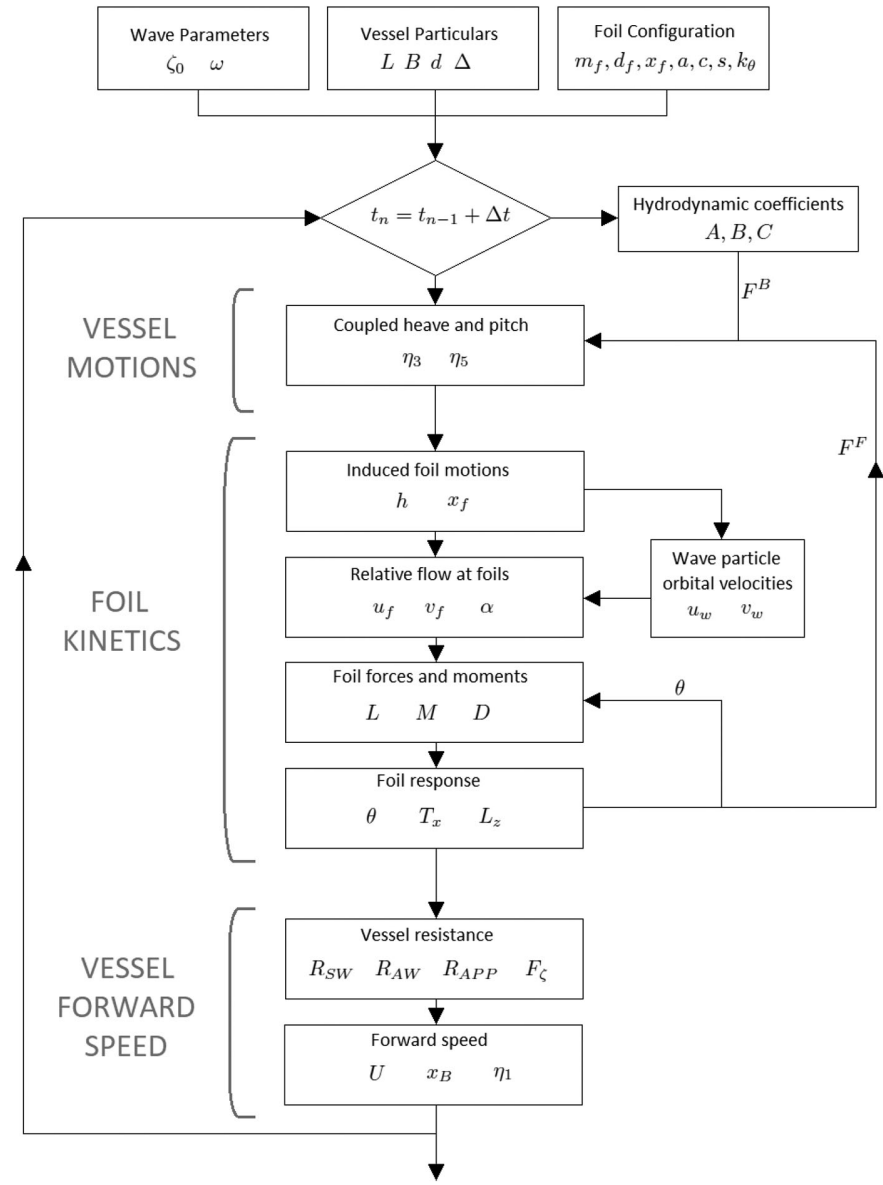

Fig. 2. Overview of the numerical model.

where the drag coefficient of the struts was estimated using Hoerner approximation [38]

$$
C_{D_{A}}=2 C_{F}\left[1+2 \frac{t_{s}}{c_{s}}+60\left(\frac{t_{s}}{c_{s}}\right)^{4}\right]
$$

where $C_{F}$ represents the ITTC' 57 friction coefficient of the strut, $t_{s}$ the strut thickness, and $c_{s}$ the strut chord. Furthermore, as the Froude number is small $\left(F_{n}<0.1\right)$, the wave making resistance and added mass $A_{11}$ were considered negligible and the waveinduced (Froude-Kriloff) surge force $\left(F_{\zeta}\right)$ was determined by integrating the incident wave pressure field over the length of the vessel as [39]

$$
F_{\zeta}=\mu_{d} \rho g k \zeta_{0} \int_{L} A_{\xi} e^{-k d_{\xi} / 2} \sin \left(k X_{\xi}\right) d \xi
$$

where $A_{\xi}$ is the hull sectional area, $X_{\xi}$ is the longitudinal distance of the hull section from the incident wave trough, $\mu_{d}$ is an empirical correction to account for the absence of diffraction effects, and $d_{\xi}$ represents the sectional draft.

\section{F. Implementation}

The hybrid discrete time-domain numerical model, summarized in Fig. 2, was implemented in MATLAB. The numerical simulations were made assuming the system started from rest, 


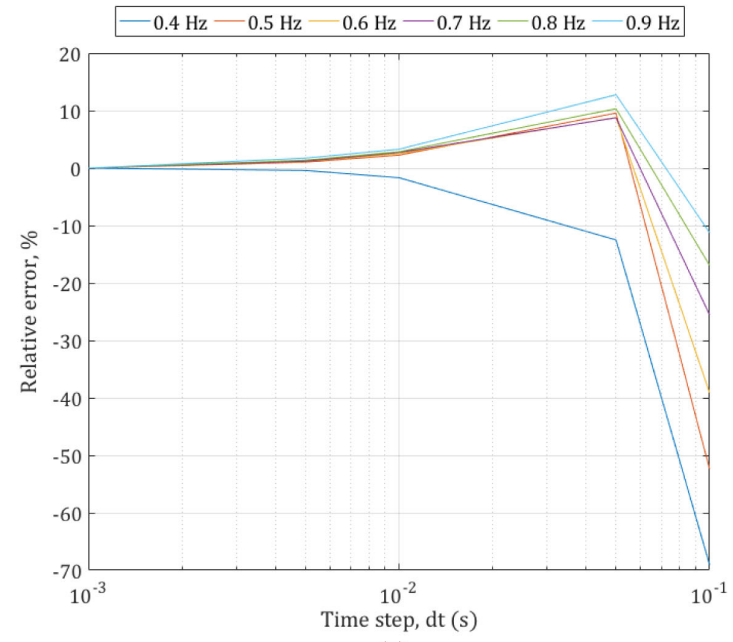

(a)

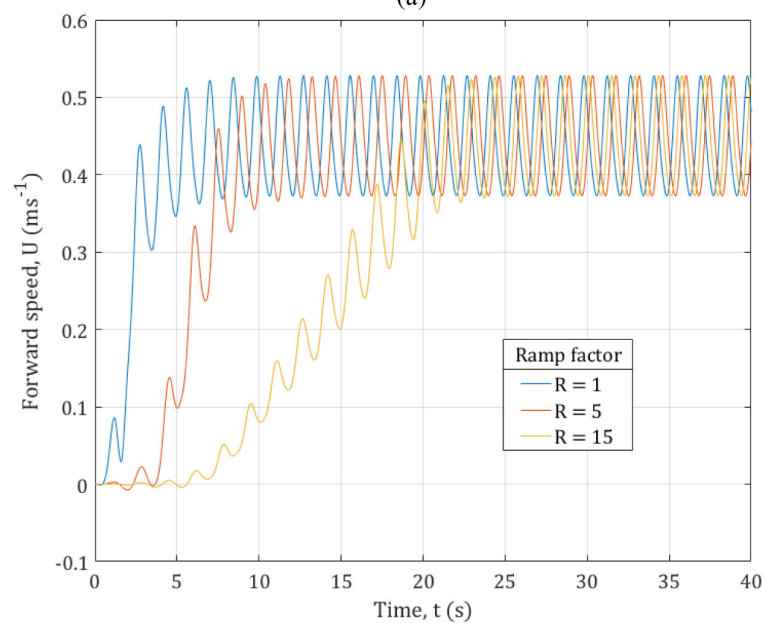

(b)

Fig. 3. Numerical model sensitivity study. (a) Effect of time step (reference $d t=0.001$ ). (b) Effect of ramp period.

with linear wave ramping (to represent the waves generated in the tank) and a time step ( $d t)$ of $0.01 \mathrm{~s}$. A time step of $0.01 \mathrm{~s}$ provided a relative error of less than 5\%, as shown in Fig. 3(a). In addition, the results were found to converge to a steady-state response irrespective of the wave ramping, as shown in Fig. 3(b), providing further confidence in the numerical model. The foil drag force $(D)$ was obtained using a lookup table of the drag coefficients $\left(C_{D}\right)$, evaluated at each time step $(d t)$ at the angle of attack $(\alpha)$, at the foil quarter chord location. The differential equations were solved using a Dormand-Prince Runge-Kutta method.

This approach, based on the quasi-steady lifting line theory in conjunction with unsteady thin hydrofoil theory, provides a computationally efficient method to assess the performance of wave-propelled boats. For greater fidelity, 3-D boundary element methods, such as those presented in [2] and [40], may offer greater accuracy, as well as estimate ship resistance. While CFD methods (e.g., 2-D/3-D RANS and 3-D DES) may yield more accurate results capturing 3-D and free-surface boundary condition effects, these approaches require significantly greater computational resource [40]; that is, the proposed method provides a useful design tool.
TABLE I

EXPERIMENTAL PROTOTYPE PARTICULARS

\begin{tabular}{|c|c|c|}
\hline Parameter & Value & Units \\
\hline Waterline length, $L_{w l}$ & 2.27 & $\mathrm{~m}$ \\
\hline Beam, $B$ & 0.34 & $\mathrm{~m}$ \\
\hline Draft, $d$ & 0.1 & $\mathrm{~m}$ \\
\hline Displacement, $\Delta$ & 45 & $\mathrm{~kg}$ \\
\hline ITTC ' 57 form factor , $k_{f}$ & 1.2 & - \\
\hline Foil mass, $m_{f}$ & 4.35 & $\mathrm{~kg}$ \\
\hline Foil chord, $c$ & 0.23 & $\mathrm{~m}$ \\
\hline Foil span, $s$ & 1 & $\mathrm{~m}$ \\
\hline Foil depth, $d_{f}$ & 0.25 & $\mathrm{~m}$ \\
\hline Foil type & NACA0012 & - \\
\hline Foil location to LCG, $x_{f}$ & $\pm 0.6,1.2,1.8$ & $\mathrm{~m}$ \\
\hline Foil pivot point & $\approx 0.01$ (from the leading edge) & $\mathrm{m}$ \\
\hline Spring constant, $k_{\theta}$ & 10 & $\mathrm{Nm} / \mathrm{rad}$ \\
\hline
\end{tabular}

\section{EXPERIMENTAL INVESTIGATIONS}

\section{A. Experimental Platform-ASV FLEUR}

To validate the numerical model, an experimental prototype (FLEUR) was developed. FLEUR, as shown in Fig. 4, is a semidisplacement slender monohull hullform with forward- and aftmounted neutrally buoyant NACA0012 foils. The foils, mounted at the end of aluminum "pivot arms," were fixed in heave and free to pitch relative to the frame and vessel using a leaf spring. The model and foil particulars are summarized in Table I.

\section{B. Experimental Procedure}

To assess the propulsive characteristics of the system, a series of free-running experiments were conducted in a towing tank (dimensions $L=60 \mathrm{~m}, W=3 \mathrm{~m}, D=1.8 \mathrm{~m}$ ) in regular head waves, over a range of wave frequencies $(0.5-0.8 \mathrm{~Hz}$ in $0.05-\mathrm{Hz}$ increments) at constant wave height $(H=0.12 \mathrm{~m})$ for three different foil locations $( \pm 0.6,1.2,1.8 \mathrm{~m}$ from the vessel $\mathrm{LCG}$, corresponding to approximately $50 \%, 100 \%$, and $150 \%$ of the half waterline length about the vessel LCG). The experimental setup is shown in Fig. 4.

The vessel motions (heave and pitch) were recorded using an XSens MTi 100 inertial measurement unit, located at the center of gravity of the model. The data were acquired at $100 \mathrm{~Hz}$ and filtered using a low-pass Butterworth filter with a cutoff frequency of $5 \mathrm{~Hz}$. The wave height, acquired at $100 \mathrm{~Hz}$, was recorded using a resistance-based wave probe. To capture the foil pitch responses, the relative motion between the trailing edge and the leading edge of each foil was measured using a video tracking software and an underwater (GoPro) camera (see Fig. 4). The video was recorded at 30 frames per second and to account for variations in distance between the model and (fixed) camera, the data points were normalized with respect to the foil chord. The flapping phase was then calculated as the phase difference between the foil pitch about the pivot point and the foil heave at the pivot point. The forward speed of the 


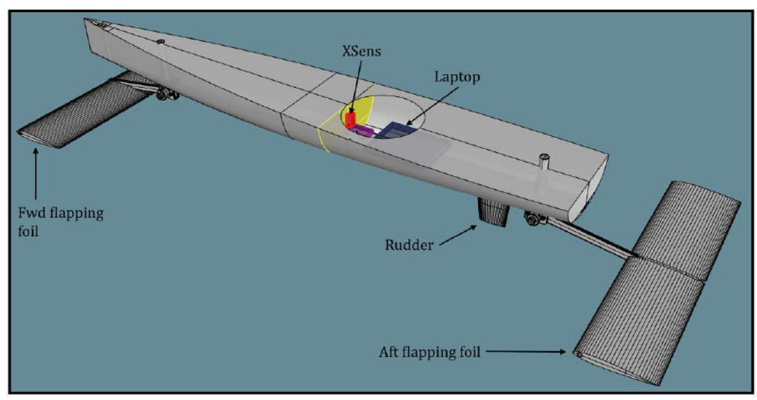

(a)

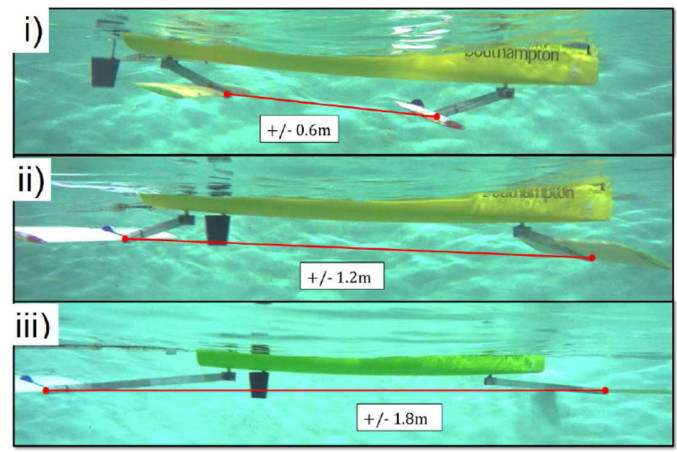

(b)

Fig. 4. Experimental prototype FLEUR. (a) CAD model. (b) Underwater photograph showing investigated foil locations ( $\pm 0.6,1.2,1.8 \mathrm{~m}$ from the vessel LCG, corresponding to approximately $50 \%, 100 \%$, and $150 \%$ of the half waterline length about the vessel LCG).

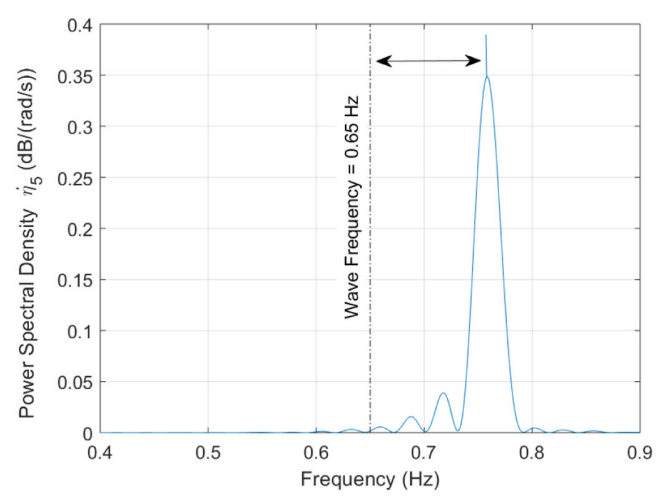

(a)

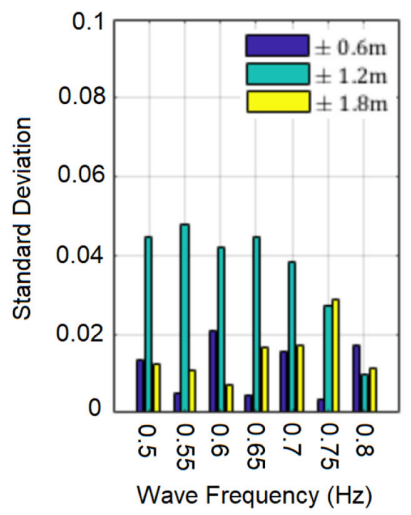

(b)

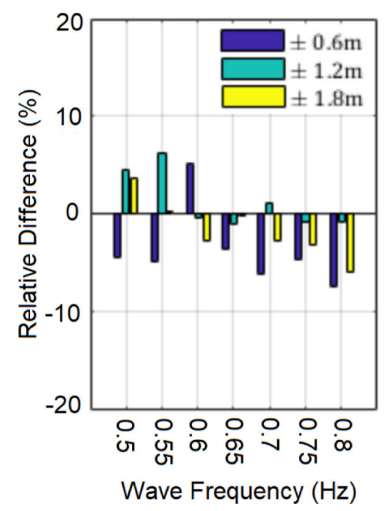

(c)

Fig. 5. Experimental repeatability. (a) Example of Doppler shift. (b) Standard deviations. (c) Comparison of Doppler method to stopwatch method.

vessel was determined from the difference between the wave frequency ( $\omega$ measured from the wave probes) and the encounter frequency ( $\omega_{e}$ measured by the accelerometer), using the identity $\omega_{e}=\omega-k U$ (see Fig. 5).

\section{RESULTS}

\section{A. Repeatability of Experimental Data}

To assess the repeatability, each experiment was conducted three times. The results, shown in Fig. 5(b), were found to be repeatable with a standard deviation of the vessel forward speed of less than 0.05 for all cases. Furthermore, comparing the average speed determined from the Doppler method (basis) and a stopwatch (the time for the vessel to travel $20 \mathrm{~m}$ within the tank), the results [see Fig. 5(c)] are in good agreement, with the relative error less than 5\% in most cases, providing confidence in the approach.

\section{B. Forward Speed}

As shown in Fig. 6, the mean forward speed of the freerunning wave-propelled boat in regular head waves was found to exhibit a frequency or resonance response with the greatest responses around $0.6 \mathrm{~Hz}$. The numerical results were found

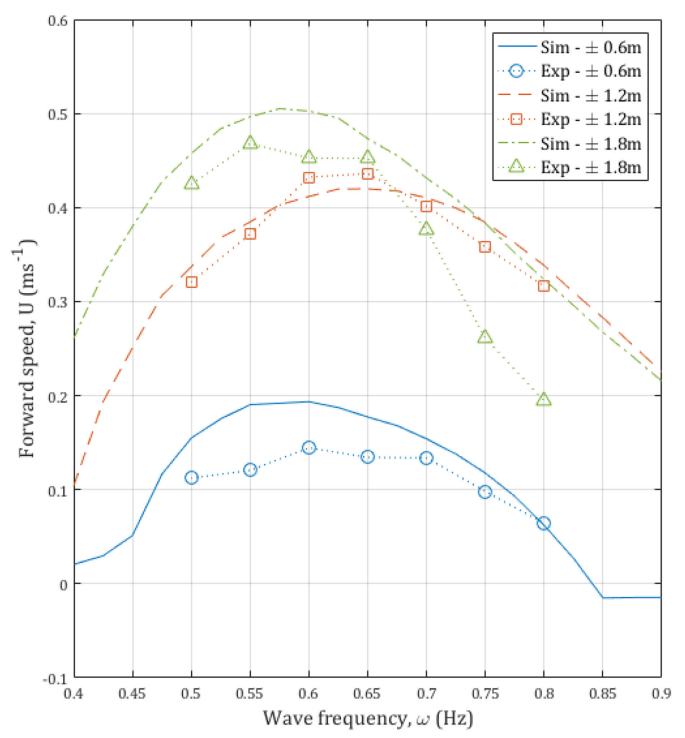

Fig. 6. Comparison of the vessel mean free-running forward speed in regular head waves.

to agree reasonably well with the experimental results, capturing the overall trends observed for all three investigated foil locations. However, at higher frequencies $(>0.7 \mathrm{~Hz})$ when the 


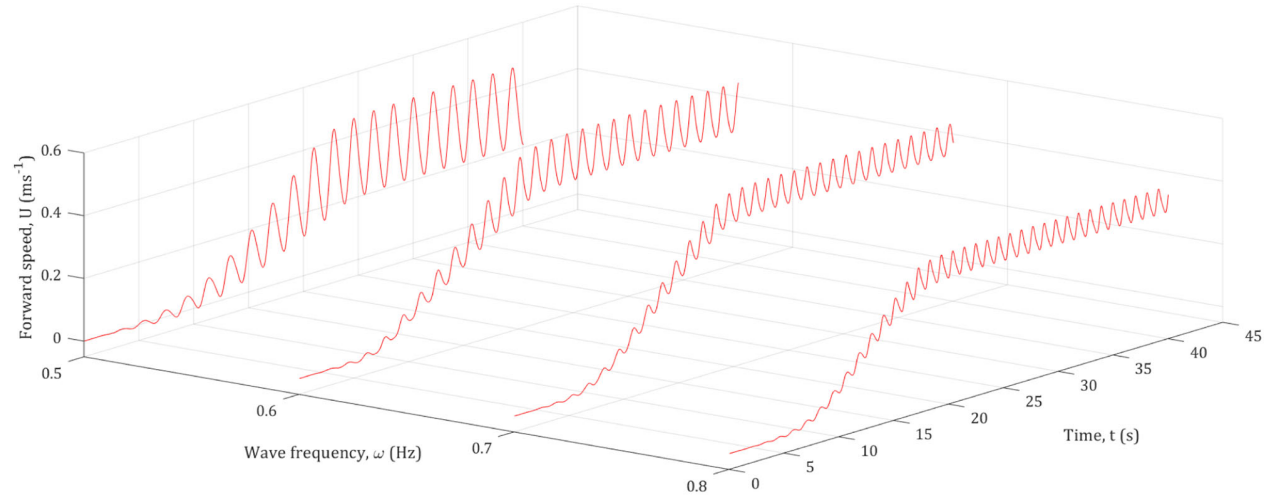

Fig. 7. Estimated vessel forward speed in regular head waves (with foils located $\pm 1.6 \mathrm{~m}$ from the LCG).

foils are located $\pm 1.8 \mathrm{~m}$ from the LCG, the numerical model appears to slightly overestimate the forward speed. At the other extreme, when the foils are located at $\pm 0.6 \mathrm{~m}$ from the LCG, the numerical model also appears to slightly overestimate the forward speed. These over estimations may be attributable to interactions between the foils and/or between the foils and the hull (e.g., the diffraction effect caused by the presence of the forward foil), which are not accounted for in the numerical model.

The instantaneous forward speed was also estimated and observed to oscillate about an equilibrium or mean speed, at the encounter frequency, as shown in Fig. 7. After the initial ramp, the amplitudes of the (steady state) oscillations in the forward speed were found to range from almost $75 \%$ of the steady state at the lower investigated frequency $(0.5 \mathrm{~Hz})$ to approximately $25 \%$ at the higher investigated wave frequencies $(0.8 \mathrm{~Hz})$; that is, the oscillations in forward speed are significant and decrease in amplitude with increasing wave frequency.

\section{Vessel Motions}

Fig. 8 shows the nondimensional heave and pitch responses of the vessel over a range of wave frequencies and foil locations. The numerical simulation results show good agreement with the experimental results, capturing the overall trends observed for all three investigated foil locations. The results clearly show that the foil location has a negligible effect on the heave response [see Fig. 8(a)] but a significant effect on the vessel pitch response [see Fig. 8(b)], demonstrating that the propulsion mechanism is pitch driven. For the investigated cases, both the experimental and numerical results show a significant pitch reduction with an increase in the foil position (relative to the LCG). Although there is a slight discrepancy in magnitude between the estimated pitch response and experimental results, the identified trends show very good agreement. The slight differences are thought to be attributable to the numerical model neglecting the interactions between the foils and/or between the foils and the hull, i.e., the diffraction or scattering of incident waves by the forward foil; that is, as the foil represents a relatively large wetted surface area in comparison to the hull, the unsteady incident wave pressure

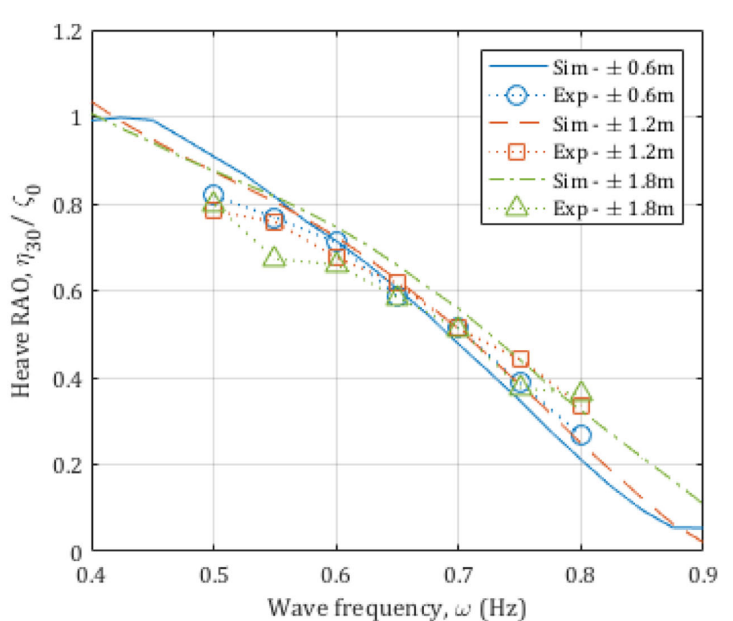

(a)

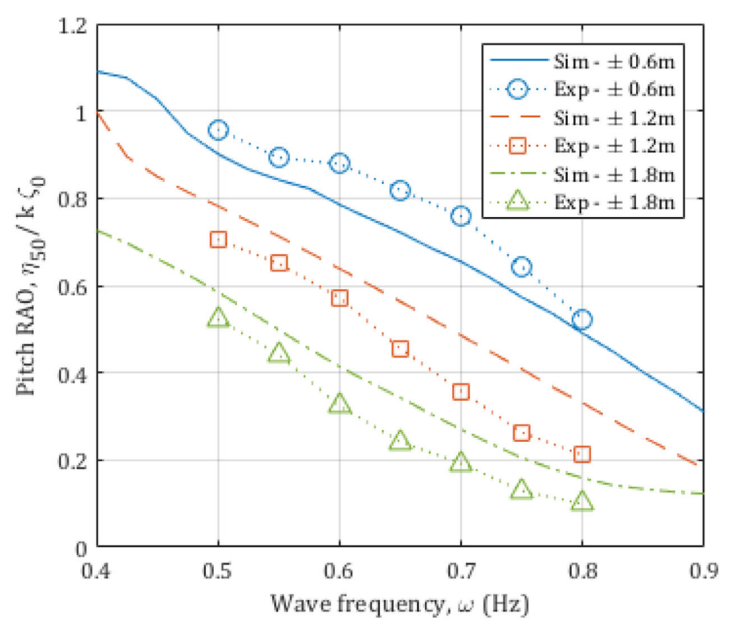

(b)

Fig. 8. Comparison of the vessel motions in regular head waves. (a) Heave response. (b) Pitch response.

acting on the hull may be expected to be significantly decreased by the presence of the forward foil, which in turn would reduce the vessel motion and forward speed. 

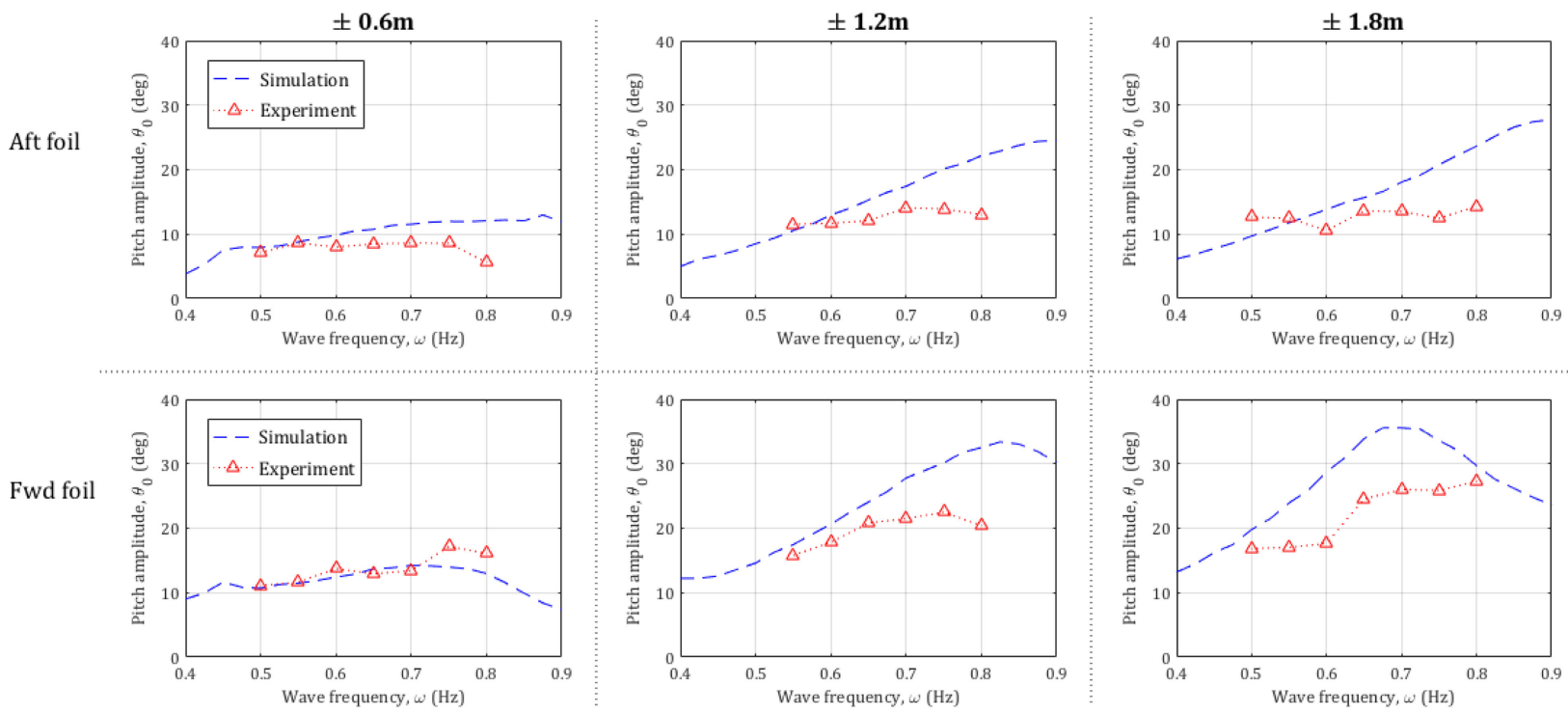

Fig. 9. Comparison of the forward and aft foil pitch amplitudes in regular head waves.
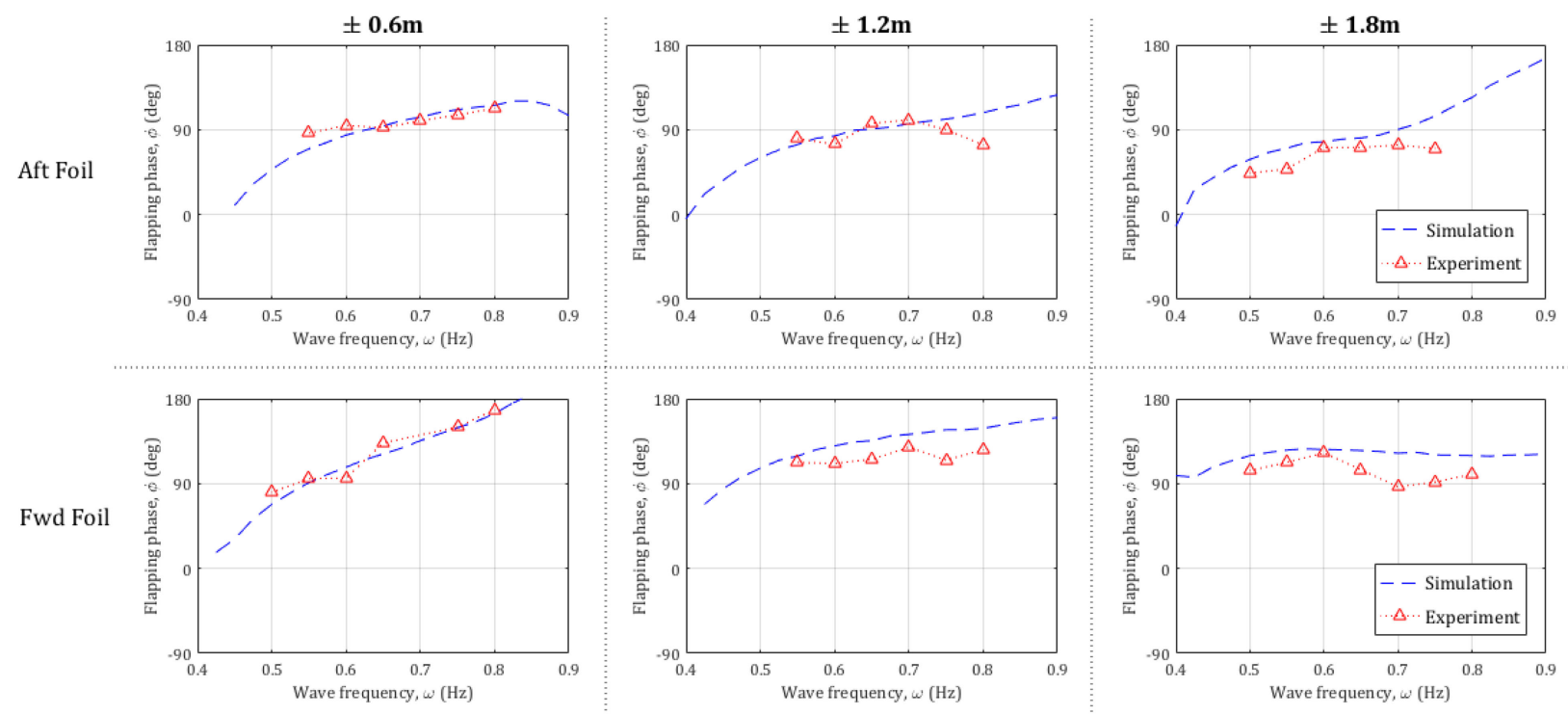

Fig. 10. Comparison of the forward and aft foil pitch flapping phases in regular head waves.

\section{Foil Motions}

Fig. 9 shows the estimated and experimentally observed pitch response $(\theta)$ of the forward and aft foils. The estimated foil responses agree reasonably well with the experimental results, exhibiting a steady increase in the foil pitch amplitude and phase with increasing wave frequency. Interestingly, the results show a noticeable difference in the flapping pitch amplitude between the forward and aft foils. The forward foil pitch amplitude was found to be significantly greater than that of the aft foil. This finding suggests that the forces acting on the forward and aft foils are different and that a greater resultant force is generated by the forward foil (than the aft foil) in regular, head waves. This implies that in head waves, a forward foil is preferable or dominant, providing greater thrust and performance gains (thrust and forward speed) could be realized through varying the forward and aft foil geometries. Fig. 10 presents the numerical and experimental results for the forward and aft foil flapping phases $(\phi)$, defined as the phase difference between the foil heave and pitch. The numerical simulation results show reasonable agreement with the experimental results, capturing the overall trends, and similarly show a noticeable difference between the forward and aft foils. The results show that the flapping phase 


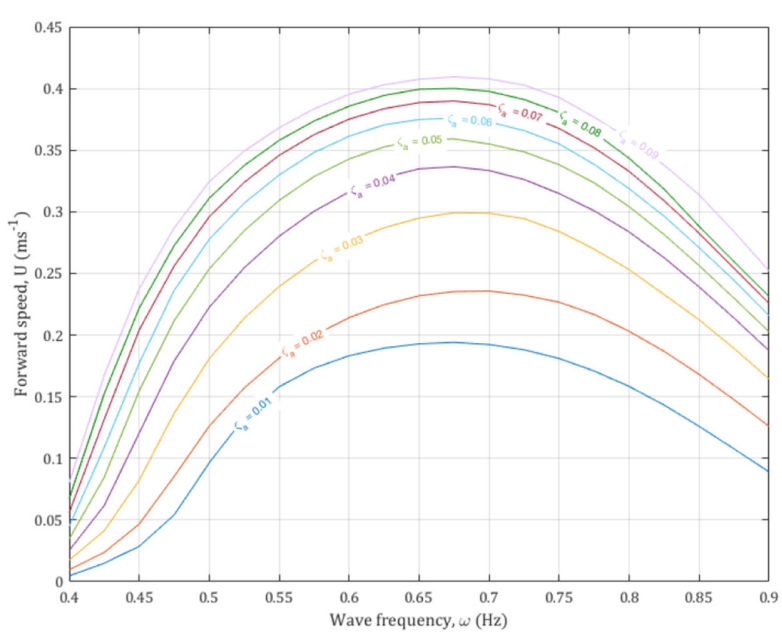

Fig. 11. Effect of wave height $\left(\zeta_{0}\right)$ on the vessel forward speed in regular head waves.

of the forward foil is considerably larger than that of the aft foil in regular head waves.

\section{DISCUSSION}

This article presented a hybrid discrete time-domain numerical model for the free-running response of a wave-propelled boat with forward and aft (tandem) flapping foils, in regular head waves, for three different foil locations. The numerical results were found to agree reasonably well with the experimental results, capturing the overall trends observed for all three investigated foil locations, validating the numerical model. Based on the numerical model, the effect of wave height, foil pitch stiffness, the vessel scale, and the induced motion mechanism (pitch or heave-driven propulsion) are discussed next to provide guidance for the design of wave-propelled vessels.

\section{A. Wave Height}

The effect of wave height on the forward speed of the vessel, the condition at which the wave-induced thrust is equal to the total resistance of the vessel, was found to plateau with increasing wave height (see Fig. 11). This finding, which also agrees with the findings of Isshiki et al. [13], shows that the total resistance increases at a greater rate than the foil thrust with wave height.

\section{B. Foil Pitch Stiffness}

Fig. 12 shows that the spring constant has a significant effect on the forward speed of the vessel. To maximize the net thrust, the spring constant needs to be selected or tuned to the given conditions, (e.g., wave frequency) or, alternatively, actively controlled. Interestingly, for fixed foil pitch (modeled as a large spring constant, which causes the foil pitch to approach zero), the foils are unable to generate sufficient thrust to overcome the hull resistance and added resistance due to waves, resulting in a negative forward speed; that is, fixed foil designs with zero

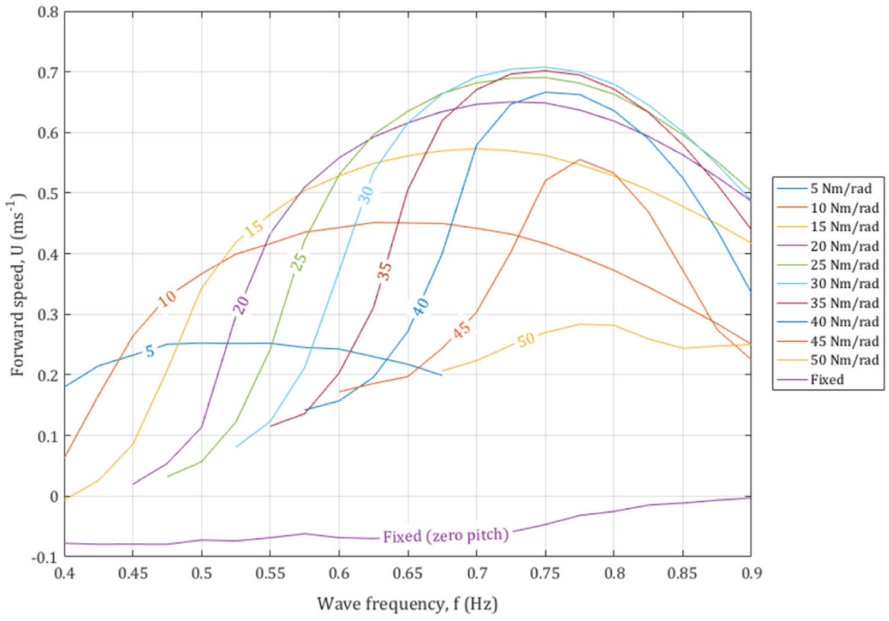

Fig. 12. Effect of spring constant $\left(k_{\theta}\right)$ on the vessel forward speed in regular head waves (foils located $\pm 1.2 \mathrm{~m}$ from the $\mathrm{LCG}, \zeta_{0}=0.06 \mathrm{~m}$ ).

pitch result in very poor propulsive performance. The results also suggest that the prototype is suboptimal and greater forward speeds could be achieved by simply varying the spring stiffness.

\section{Vessel Scale}

The effect of vessel scale has a significant influence on the vessel forward speed. As shown in Fig. 13(a), there is a typical resonance response with larger vessels more suited to low-frequency waves, over a narrow range and smaller vessels more suited to higher frequency waves, with a wider range. This suggests that the optimal passive design (size) of a wave-powered vessel, should be selected based on the operational wave conditions. Presenting the results non-dimensionally (Froude number $F_{n}$ against $\lambda / L_{\mathrm{wl}}$, as shown in Fig. 13(b), the results collapse to one curve with an optimum wavelength to length ratio, of approximately 1.25 , for head waves. In comparison, an optimum ratio of 1.05 in head waves assuming a fixed forward speed is reported in [41]. This finding suggests that the free-running aspects (e.g., the oscillatory motions and the frequency shift) are important to accurately model the performance.

\section{Pitch Versus Heave Driven Propulsion}

Fig. 14 compares the performance (forward speed over a range of a wave frequencies) of a heave induced system (e.g., Waveglider) to the investigated pitch-induced system (e.g., AutoNaut). For comparison, both systems were assumed to be identical (having two identical foils and hull parameters). To model the heave driven system, the numerical model was adapted by removing the pitch-induced foil response and assuming the foils were submerged $5 \mathrm{~m}\left(2.2 L_{\mathrm{wl}}\right)$, located beneath the LCG. The results, as shown in Fig. 14, show that average forward speeds are comparable, however with a significant difference in their resonance response. The pitch-driven system suited to a higher wave frequency $\left(\lambda / L_{\mathrm{wl}}=1\right)$, and a heave-induced 


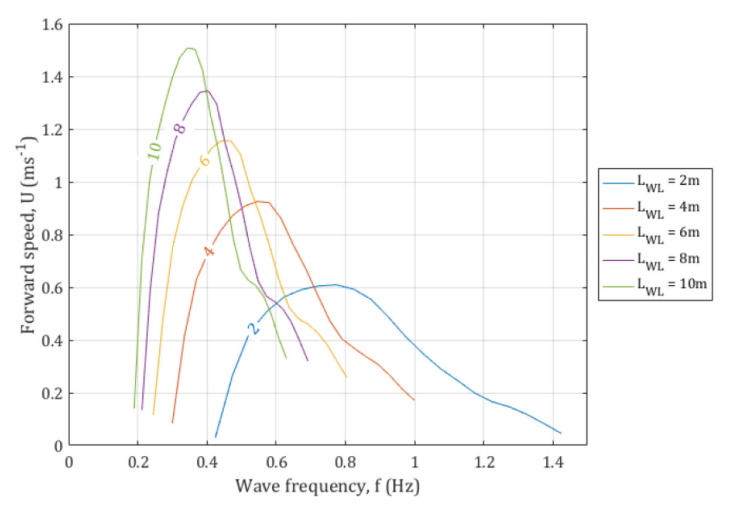

(a)

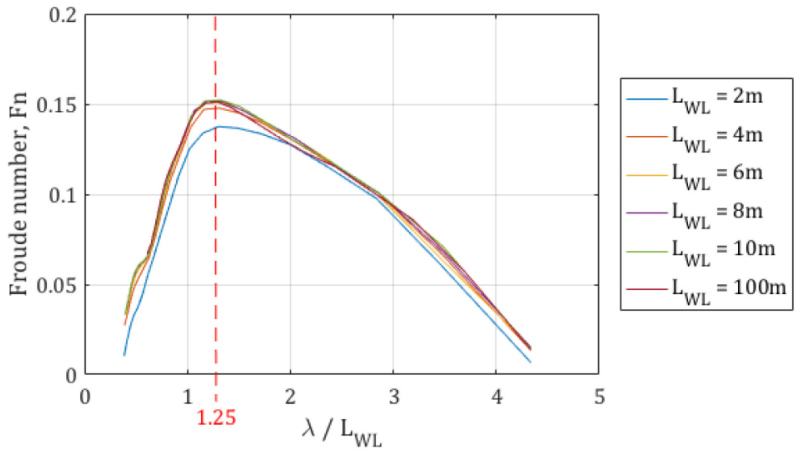

(b)

Fig. 13. Geometric scaling effect on the vessel forward speed in regular head waves. (a) Over a range of vessel sizes. (b) Nondimensional representation (Froude number $F_{n}$ against $\lambda / L_{w l}$ ) (foils located at $\pm 1.2 \mathrm{~m}$ from the $\mathrm{LCG}, \zeta_{0}=0.06 \mathrm{~m}, k_{\theta}=10 \mathrm{~N} \cdot \mathrm{m} / \mathrm{rad}$ ).

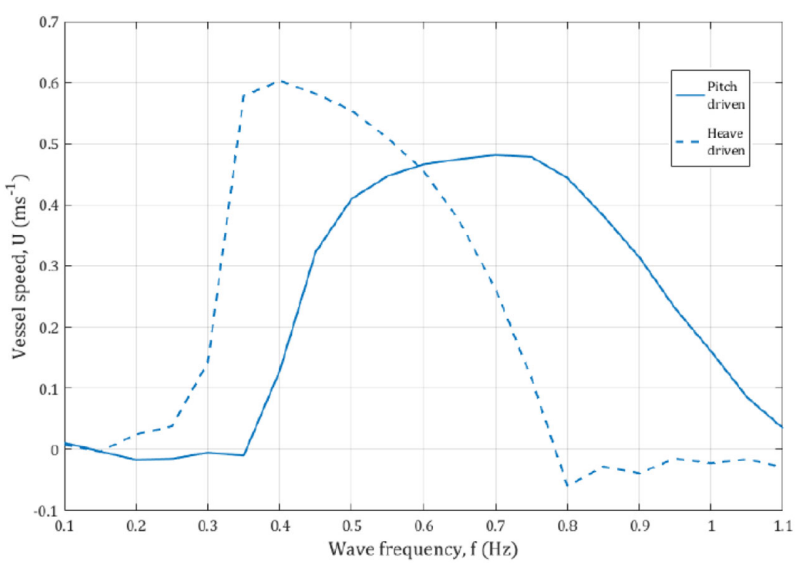

Fig. 14. Forward speed comparison of a pitch-driven and heave-driven mechanism in head waves (at $0.5-\mathrm{Hz}$ intervals) (Foils located at $\pm 1.2 \mathrm{~m}$ from the $\left.\mathrm{LCG}, \zeta_{0}=0.06 \mathrm{~m}, k_{\theta}=10 \mathrm{~N} \cdot \mathrm{m} / \mathrm{rad}\right)$.

mechanism suited to a lower wave frequency $\left(\lambda / L_{w l}=5\right)$, albeit with a large crossover.

\section{CONCLUSION}

This article presented a hybrid discrete time-domain numerical model and experimental results from a prototype wavepropelled boat with forward and aft (tandem) flapping foils, in regular head waves. The numerical simulations were found to show good agreement with the experimental results, capturing the overall trends observed, for all investigated cases. The results confirmed that the propulsion mechanism is pitch driven, with the location of the foils having a significant effect on the vessel pitch response and negligible effect on the vessel heave. In addition, the results identified that the free-running forward speed response oscillates around a mean forward speed, and the amplitude of this oscillation is significant representing between $25 \%$ and $75 \%$ of the steady-state mean speed, decreasing with increasing wave frequency. Furthermore, the results identified a significant difference between the foil contributions, with the forward foil pitch amplitude found to be significantly greater than that of the aft foil in regular head waves. This implies that in head waves, a forward foil is preferable or dominant, providing greater thrust and performance gains (thrust and forward speed) could be realized through varying the forward and aft foil geometries. The model, which represents a step toward a complete velocity prediction program for wave-propelled boats, provides a valuable insight and design tool for the development of wave-propelled boats.

\section{REFERENCES}

[1] E. Bøckmann and S. Steen, "Model test and simulation of a ship with wavefoils," Appl. Ocean Res., vol. 57, pp. 8-18, 2016.

[2] K. A. Belibassakis and G. K. Politis, "Hydrodynamic performance of flapping wings for augmenting ship propulsion in waves," Ocean Eng., vol. 72, pp. 227-240, 2013.

[3] P. Johnston and M. Poole, "Marine surveillance capabilities of the AutoNaut wave-propelled unmanned surface vessel (USV)," in Proc. MTS/IEEE OCEANS Conf., Aberdeen, Scotland, 2017, pp. 1-46.

[4] J. Bowker, N. Townsend, M. Tan, and R. Shenoi, "Experimental analysis of submerged flapping foils; implications for autonomous surface vehicles (ASVs)," in Proc. MTS/IEEE OCEANS Conf., Monterey, CA, USA, 2016, pp. $1-10$.

[5] H. Linden, "Improved combination with floating bodies, of fins adapted to effect their propulsion," GB Patent GBD189514630, Jul. 18, 1896.

[6] "Wave power runs model boat," Popular Sci., vol. April, p. 26, 1935.

[7] "Waves serve as boat's engine," Popular Sci., p. 224, 1950.

[8] “Mr. Gause's incredible self-propelled boat!” Mech. Illustrated, p. 22 and $179,1972$.

[9] E. Jakobsen, "The foil propeller, wave power for propulsion," in Proc. 2nd Int. Symp. Wave Tidal Energy, 1981, pp. 363-368,.

[10] K. Dybdahl, "Foilpropellen kan revolusjonere skipsfarten," Teknisk Ukeblad/Teknikk, vol. 39, pp. 10-11, 1988.

[11] M. Nikolaev, A. Savitskiy, and Y. Senkin, "Basics of calculation of the efficiency of a ship with propulsor of the wing type," Sudostroenie, vol. 4, pp. 7-10, 1995.

[12] Y. Terao, "A floating structure which moves towards the waves (possibility of wave devouring propulsion)," J. Kansai Soc. Nav. Archit., vol. 184, pp. 51-54, 1982.

[13] H. Isshiki et al., "Wave energy utilization into ship propulsion by fins attached to a ship," in Proc. 4th Int. Offshore Polar Eng. Conf., 1994, pp. 508-521.

[14] J. Geoghegan, "Wave runner: A new propulsion system for boats ditches diesel," Popular Sci., vol. 272, no. 3, 2008.

[15] Y. Terao and N. Sakagami, "Application of wave devouring propulsion system for ocean engineering," in Proc. ASME 32nd Int. Conf. Ocean, Offshore Arctic Eng., 2013, Paper OMAE2013-10691.

[16] Y. Terao and N. Sakagami, "Design and development of an autonomous wave-powered boat with a wave devouring propulsion system," Adv Robot., vol. 29, no. 1, pp. 89-102, 2015. 
[17] R. Hine, S. Willcox, G. Hine, and T. Richardson, "The wave glider: A wave-powered autonomous marine vehicle," in Proc. IEEE OCEANS Conf., 2009, pp. 1-6.

[18] "Wavefoil AS." Accessed on: Dec. 9, 2019. [Online]. Available: https: //wavefoil.com

[19] P. Liu, Y.-M. Su, and Y.-L. Liao, "Numerical and experimental studies on the propulsion performance of a wave glide propulsor," China Ocean Eng., vol. 30, no. 3, pp. 393-406, 2016.

[20] Z. Yu, Z. Zheng, X. Yang, and Z. Chang, "Dynamic analysis of propulsion mechanism directly driven by wave energy for marine mobile buoy," Chin. J. Mech. Eng., vol. 29, no. 4, pp. 710-715, 2016.

[21] B.-Q. Tian, J.-C. Yu, and A.-Q. Zhang, "Dynamic modeling of wave driven unmanned surface vehicle in longitudinal profile based on DH approach," J. Central South Univ., vol. 22, no. 12, pp. 4578-4584, 2015.

[22] C.-L. Zhou, B.-X. Wang, H.-X. Zhou, J.-L. Li, and R. Xiong, "Dynamic modeling of a wave glider," Frontiers Inf. Technol. Electron. Eng., vol. 18, no. 9, pp. 1295-1304, 2017.

[23] P. Ngo, J. Das, J. Ogle, J. Thomas, W. Anderson, and R. N. Smith, "Predicting the speed of a wave glider autonomous surface vehicle from wave model data," in Proc. IEEE/RSJ Int. Conf. Intell. Robots Syst., 2014, pp. 2250-2256.

[24] J. Liu, Y. Li, H. Yi, and Y. Zhang, "The modeling and analysis of wave powering surface vehicle," in Proc. MTS/IEEE KONA OCEANS Conf., 2011, pp. 1-6.

[25] T. Wu et al., "Extraction of flow energy by a wing oscillating in waves," J. Ship Res., vol. 16, no. 1, pp. 66-78, 1972.

[26] H. Xie et al., "Hydrodynamic performance of tandem oscillating foils in waves," in Proc. 27th Int. Ocean Polar Eng. Conf., 2017.

[27] H. Isshiki and M. Murakami, "A theory of wave devouring propulsion (4th report)," J. Soc. Nav. Archit. Japan, vol. 156, no. 156, pp. 102-114, 1984

[28] E. Bøckmann, "Wave propulsion of ships," PhD thesis, Norwegian Univ. Sci. Tech., 2015

[29] K. Belibassakis and E. Filippas, "Ship propulsion in waves by actively controlled flapping foils," Appl. Ocean Res., vol. 52, pp. 1-11, 2015.

[30] S. Naito, H. Isshiki, and K. Fujimoto, "Thrust generation of a Fin Attached to a Ship in Waves," J. Kansai Soc. Nav. Archit., vol. 202, pp. 23-29, 1986.

[31] B. Software, "MAXSURF motions advanced and MAXSURF resistance [computer program]," 2014. [Online]. Available: https://www.bentley. com/en/products/product-line/offshore-structural-analysis-software/ maxsurf

[32] N. Salvesen, E. Tuck, and O. Faltinsen, "Ship motions and sea loads," Trans. SNAME, vol. 78, no. 8, pp. 250-287, 1970.

[33] J. Katz and A. Plotkin, Low-Speed Aerodynamics, vol. 13. Cambridge, U.K.: Cambridge Univ. Press, 2001.

[34] T. Theodorsen, "General theory of aerodynamic instability and the mechanism of flutter," Nat. Adv. Committee Aeronaut., Washington, DC, USA, Tech. Rep. 496, pp. 413-433, 1934.

[35] International Towing Tank Conference (ITTC), Proc. 8th ITTC, Canal de Experiencias Hidrodinamicas, El Pardo, Madrid, Spain, 1957.

[36] F. P. Arribas, "Some methods to obtain the added resistance of a ship advancing in waves," Ocean Eng., vol. 34, no. 7, pp. 946-955, 2007.

[37] P. D. Sclavounos and H. Borgen, "Seakeeping analysis of a high-speed monohull with a motion-control bow hydrofoil," J. Ship Res., vol. 48, no. 2 , pp. $77-117,2004$
[38] S. F. Hoerner, "Fluid dynamic drag, published by the author, 1965," in Library Congr. Catalog Card (No. 57-13009), 1992.

[39] H. Hashimoto, S. Yoneda, Y. Tahara, and E. Kobayashi, "CFD-based study on the prediction of wave-induced surge force," Ocean Eng., vol. 120, pp. 389-397, 2016.

[40] G. Papadakis, E. Filippas, D. Ntouras, and K. Belibassakis, "Effects of viscosity and nonlinearity on 3D flapping-foil thruster for marine applications," in Proc. IEEE OCEANS Conf., Marseille, France, 2019, pp. 1-10.

[41] G. Konstantinov and Y. L. Yakimov, "Calculation of the thrust of a wavepowered marine propelling device," Fluid Dyn., vol. 30, no. 3, pp. 453-456, 1995.

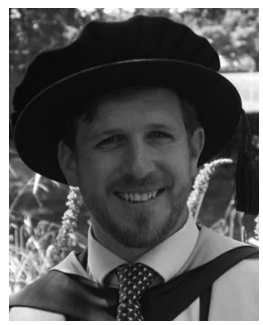

James A. Bowker received the M.Eng. degree in ship science and the Ph.D. degree in coupled dynamics of a flapping foil wave-powered vessel from the University of Southampton, Southampton, U.K, in 2012 and 2018, respectively.

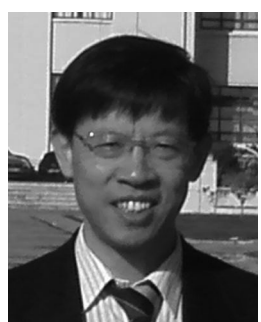

Mingyi Tan received the B.Sc. and M.Eng. degrees in engineering mechanics from Tsinghua University, Beijing, China, in 1982 and 1984 respectively, and the $\mathrm{Ph} . \mathrm{D}$. degree in computational fluid dynamics from the University of Southampton, Southampton, U.K., in 1994.

$\mathrm{He}$ is currently a Lecturer in ship science with the Faculty of Engineering and Physical Sciences, University of Southampton, with a background in applied mechanics, numerical analysis, and computer simulations.

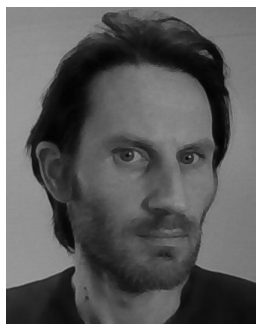

Nicholas Charles Townsend received the M.Eng. degree in mechanical engineering from the University of Birmingham, Birmingham, U.K., in 2003, and the Engineering Doctorate (EngD) degree in influencing and influences of marine vessel motions from the University of Southampton, Southampton, U.K., in 2008.

$\mathrm{He}$ is currently a Lecturer in ship science with the Faculty of Engineering and Physical Sciences, University of Southampton. 